\title{
CISTITIS FOLICULAR. APORTACIÓN DE UN CASO Y REVISIÓN DE LA LITERATURA
}

\author{
F. DOMÍNGUEZ FREIRE, A. NÚÑEZ LÓPEZ, A. ALONSO RODRIGO, \\ B. RODRÍGUEZ IGLESIAS, J. BENAVENTE DELGADO, J.M. BARROS RODRÍGUEZ, \\ A. OJEA CALVO
}

Servicio de Urología. Hospital Universitario Xeral-Cies de Vigo. Vigo. Pontevedra.

Actas Urol Esp. 27 (7): 551-554, 2003

\section{RESUMEN}

CISTITIS FOLICULAR. APORTACIÓN DE UN CASO Y REVISIÓN DE LA LITERATURA

OBJETIVO: Aportar un caso clínico con el diagnóstico de cistitis folicular y revisar la literatura sobre el tema.

CASO CLÍNICO: Paciente de 78 años de edad, diagnosticado de cáncer de próstata, portador de sonda de forma permanente por retención urinaria. Se indica resección transuretral desobstructiva de próstata, realizándose al mismo tiempo resección y estudio anatomopatológico de múltiples formaciones con aspecto nodular, situadas en el trígono y caras laterales de la vejiga. El diagnóstico fue cistitis folicular.

CONCLUSIONES: La cistitis folicular es un tipo de cistitis crónica inespecífica que se caracteriza por un intenso infiltrado inflamatorio a expensas de linfocitos y células plasmáticas que se agrupan formando folículos en la submucosa vesical. Continúa vigente la indefinición en la etiopatogenia, tratamiento y pronóstico de esta patología. Tan sólo la certeza del diagnóstico histológico confirma su entidad.

PALABRAS CLAVE: Cistits folicular. Cistitis crónica. Cistitis.

\section{ABSTRACT}

CYSTITIS FOLICULAR. A CASE REPORT AND REVIEW OF THE LITERATURE

OBJECT: We report a patient with cystitis follicularis and review the literature about it.

CLINICAL CASE: A man 78 years old with prostate cancer, who need a permanent bladder catheter. We make a desobstructive TUR, prostate resection and many nodular lesions in the lateral walls and bladder down. The diagnostic was cystitis follicularis.

CONCLUSIONS: The cystitis follycularis is a cystitis inespecific and cronic kind with a important inflammation made of linphocytos and plasmatic cells. Its makes linphoydes foliculos in the bladder subepithelial wall. The indefination its alive about cystitis follicularis etiopageny, treatment and pronostic. The histopatology study is neccesary.

KEY WORDS: Cystitis follicularis. Cystitis cronic. Cystitis.

$\mathrm{L}^{\mathrm{a} a \mathrm{at}}$ a patología inflamatoria e infecciosa que afecta a la mucosa vesical clásicamente se ha denominado cistitis. La cistitis folicular es un tipo de cistitis inespecífica crónica que se caracteriza por la presencia en el tejido conectivo submucoso de gran cantidad de células plasmáticas y linfocitos que se organizan formando folículos linfoides con centros germinativos en su interior.
De etiología incierta, es necesaria una irritación crónica de la mucosa vesical para su aparición. Los folículos se aprecian macroscópicamente como nódulos sólidos, ligeramente sonrosados, que pueden ser confundidos con formaciones neoplásicas. Realizamos una revisión del tema mediante búsqueda en Medline de la literatura publicada. 


\section{CASO CLÍNICO}

Presentamos el caso de un varón de 78 años de edad, con antecedentes de hipertensión arterial y artropatía crónica, controlado en la consulta externa con el diagnóstico de adenocarcinoma de próstata a tratamiento con bloqueo androgénico completo. El paciente precisaba sonda vesical permanente. Se decidió realizar resección transuretral desobstructiva, durante la cual, se objetiva una extensa área sobre la mucosa del trígono y caras laterales de la vejiga con lesiones de aspecto nodular, sobre-elevadas, de consistencia sólida y ligeramente enrojecidas (Fig. 1). Se practicó resección transuretral de la próstata y biopsia de las lesiones descritas en la vejiga . El estudio anatomopatológico revela una mucosa vesical cuyo epitelio de revestimiento superficial aparece conservado. Subyacente a dicho urotelio, se aprecia un intenso infiltrado inflamatorio crónico compuesto exclusivamente por células linfoides que se organizan formando auténticos folículos linfoides con centros claros germinativos, todo ello se corresponde con el diagnóstico de cistitis folicular (Fig. 2).

\section{DISCUSIÓN}

Las cistopatías inflamatorias no neoplásicas constituyen un tipo de patología de difícil sospecha diagnostica puesto que no se asocian con una sintomatología característica, por lo que el paciente suele ser diagnosticado incidentalmente. La cistopatía folicular exige para su correcto diagnóstico la presencia en el estudio anatomopatológico de folículos linfáticos con centros germinativos en el material de una biopsia vesi$\mathrm{cal}^{1,2,11}$. Estos folículos fueron descritos por primera vez por Cruveilhier ${ }^{3}$ en 1856 y posteriormente por Rokitansky en $1860^{4}$ y Von Recklinhausen en $1862^{5}$. La incidencia de la cistopatía folicular es excepcional. Una vez revisada la literatura publicada, se pone de manifiesto la baja incidencia de esta entidad por el escaso número de casos publicados. En nuestro país destaca, sin embargo, una serie de 26 casos publicada por el grupo de la Fundación Puigvert recogida entre 1982 y $1996^{2}$. En esta serie, al igual que en la casuística del resto de autores consultados $^{1,2,6,7,11-14}$, predomina el sexo femenino y la mayor incidencia en la $5^{\mathbf{a}}$ década de la vida. En la mayoría de las ocasiones se habla de

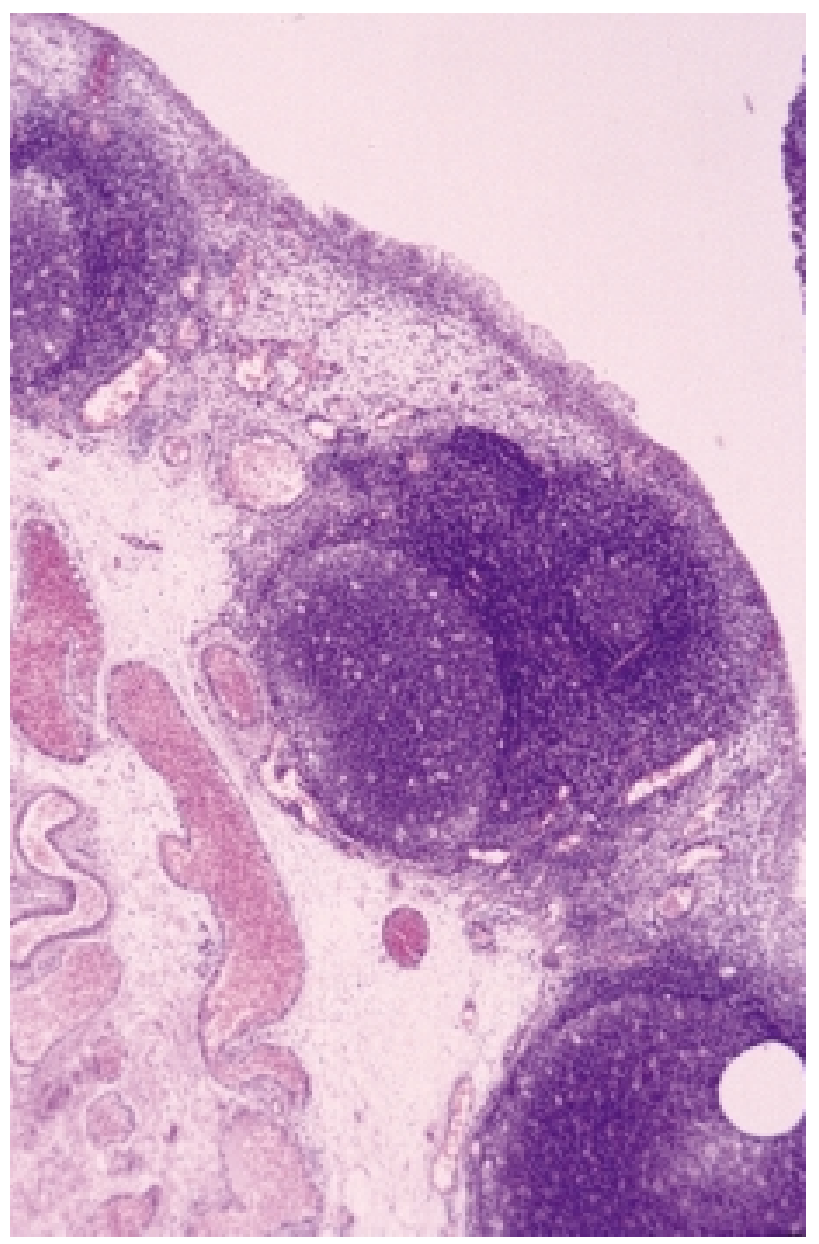

FIGURA 1. Imagen del estudio anatomopatológico de las muestras de la biopsia vesical. Se aprecia un intenso infiltrado inflamatorio crónico compuesto exclusivamente por células linfoides que se organizan formando foliculos linfoides con centros claros germinativos.

cistopatía más que de cistitis ya que no se logran identificar agentes infecciosos.

De etiología incierta, se han implicado varias posibilidades como causa de esta patología, coincidiendo los distintos autores ${ }^{1,2,6,7,11}$, en la necesidad de una irritación crónica de la mucosa vesical como paso previo a la aparición de las lesiones histopatológicas que la caracterizan. Esta irritación o estímulo previo ha sido identificado como infecciones de repetición, litiasis, patología neoplásica vesical o sondaje vesical prolongado. Frente a estos estímulos, la mucosa vesical reacciona con la formación de los folículos linfáticos que caracterizan a esta patología. En la aparición de los folículos también se han implicado fenómenos de carácter inmunológico, sugiriendo que la mucosa vesi- 


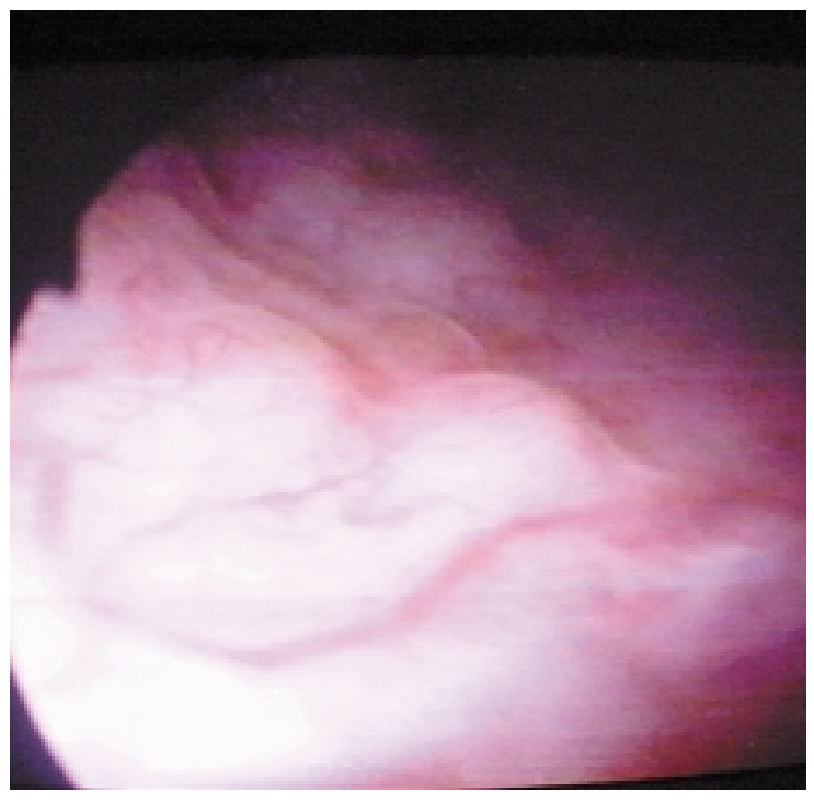

FIGURA 2. Imagen endoscópica: lesiones de aspecto nodular, sobrelevadas, de consistencia sólida y ligeramente enrojecidas.

cal de los pacientes con cistopatía folicular tendrían la capacidad de secretar inmunoglobulinas ${ }^{2,11}$.

La clínica es inespecífica, consiste en un síndrome miccional irritativo. Su diagnóstico es casi siempre incidental. La descripción de la semiología endoscópica nos parece el aspecto más importante por su implicación en la práctica clínica. La imagen cistoscópica presenta múltiples lesiones sobre-elevadas de aspecto nodular, ligeramente enrojecidas y aparentemente sólidas que se disponen habitualmente en la zona adyacente al trígono y mitad inferior de las paredes laterales de la vejiga, disminuyendo a medida que nos alejamos del cuello vesical ${ }^{1}$. Estas lesiones están recubiertas por mucosa lisa de aspecto normal.

$\mathrm{Su}$ diagnostico diferencial debe incluir al resto de cistopatías no neoplásicas ${ }^{1,2,15}$ como la cistopatía glandular, la cistopatía quística, la cistopatía polipoide, la leucoplasia vesical, la bilharziosis o los tuberculomas vesicales. Las cistopatías glandular y quística presentan formaciones que se asemejan más a lo que entendemos por quistes, redondeadas y traslúcidas en la quística y de coloración pardo-verdosa en la glandular ${ }^{1,2}$. En esta última se puede incluso encontrar mucosidad en la superficie mamelonada de los nódulos vesicales. La cistopatía polipoidea presenta nódulos de mayor tamaño y de aspecto edematoso semejando una formación sólida pseudotumoral ${ }^{2,14,15}$. Otras entidades, como los tuberculomas vesicales, de disposición típicamente perimeática y la bilharziosis, son más fácilmente diagnosticables mediante la historia clínica y las pruebas complementarias ${ }^{1}$. Por último, la leucoplasia vesical presenta zonas más o menos extensas de tejido epidermoide con estrato córneo que aparecen como transformación del epitelio normal de la vejiga, y que forman placas bien delimitadas de color blanquecino ${ }^{1}$.

Para establecer el diagnóstico definitivo de la cistopatía folicular es imprescindible el estudio histopatológico de biopsias obtenidas de la mucosa vesical. Además de acúmulos de folículos linfoides en la submucosa es necesaria la presencia de centros germinales.

El tratamiento implica la eliminación de los factores irritativos. En algunos casos además de tratamiento antibiótico para eliminar los gérmenes existentes se puede administrar vitamina A e incluso realizar lavados vesicales con analgésicos, anti-inflamatorios o anestésicos locales ${ }^{2}$.

$\mathrm{Su}$ pronóstico es benigno, ya que no se ha encontrado predisposición a la aparición de patología neoplásica, exceptuando los casos que ya tenían previamente neoplasias asociadas.

Se ha sugerido una posible relación entre la cistopatía folicular y el linfoma vesical, si bien no existen suficientes casos publicados que confirmen esta asociación ${ }^{8,9,10}$. A pesar de los años transcurridos desde la primera descripción realizada por Cruveilhier ${ }^{3}$, continúa vigente la indefinición en la etiopatogenia, tratamiento y pronóstico de la cistopatía folicular. Tan sólo la certeza del diagnóstico histológico confirma su entidad.

\section{REFERENCIAS}

1. CIFUENTES DELATTE L.: Cistitis y cistopatías (segunda edición). Edit Bok, S.A. Madrid 1989: 5966.

2. VICENTE J, ALGABA F.: Semiología diagnóstica endovesical. Ediciones Pulso, S.A. Madrid 1998: 6672.

3. CRUVEILHIER: Citado por Vicente J, Algaba F.: Semiología diagnóstica endovesical. Ediciones Pulso, S.A. Madrid 1998: 66-72.

4. ROKITANSKY: Citado por Vicente J, Algaba F.: Semiología diagnóstica endovesical. Ediciones Pulso, S.A. Madrid 1998: 66-72.

5. VON RECKLINHAUSEN: Citado por Vicente J, Algaba F.: Semiología diagnóstica endovesical. Ediciones Pulso, S.A. Madrid 1998: 66-72. 
6. HINMAN F, CORDONIER J.: Cystitis follicularis. $J$ Urol 1935; 34: 302.

7. SARMA KP.: On the nature of cystitis follicularis. $J$ Urol 1970 nov; 104 (5): 709-714.

8. AQUILINA JW, BUGUEJA TJ.: Priamary malignant limphoma of the bladder; a case report and review of the literature. J Urol 1974; 112: 64.

9. PAWADE J, BANERYEE SS, HARRIS M et al.: Lymphomas of mucosa-associated lymfoid tissue arising in the urinary bladder. Hystopathology 1993 aug; 23 (2): 147-151.

10. OOHSAWA M, AOZASA $\mathrm{K}$, HORIUCHI $\mathrm{K}$ et al.: Malignant lymphoma of bladder. Report of three cases and review of the literature. Cancer $1993 \mathrm{sep}$ 15; 72 (6): 1969-1974.

11. MANDAL AK.: Follicular cystitis-a case report. Indian J Pathol Microbiol 1999 oct; 42 (4): 503-504.

12. HANSSON S, HANSSON E, HJALMAS MJ.: Follicular cystitis in girls with untreated assymptomatic or cover bacteriuria. J Urol 1990; 143: 330332.
13. BROCK WA, SMOL KO, EVANS KJC et al.: Cystitis follicularis in children with primary vesico ureteral reflux. J Urol 1983 may; 129 (5): 1020-1021.

14. DUARTE NOVO JE, PATIÑO ML, RUIBAL MOLDES M, ÁLVAREZ CASTELO L, LANCINA MARTÍN A, GONZÁLEZ MARTÍN M.: Cistitis folicular. Presentación como pseudotumor vesical. Actas Urol Esp 1998; 22 (1): 67-69.

15. VARO SOLIS C, BACHILLER BURGOS JM, BÁEZ JM, ESTUDILLO F, GONZÁLEZ MORENO D, ÁLVAREZ-OSORIO FERNÁNDEZ JA, JUAREZ SOTO A, SOTO DELGADO M, BELTRÁN AGUILAR VM.: Consideraciones sobre la cistitis quística glandular. Actas Urol Esp 2000; 24 (7): 594-598.

Dr. F. Domínguez Freire

Rua Don Marcial no 11

36391 Priegue. Nigrán (Pontevedra)

(Trabajo recibido el 3 septiembre de 2003) 